\title{
(Re)Significaçóes no Processo de Avaliação do Sujeito Jovem e Adulto COM DEFICIÊNCIA INTELECTUAL ${ }^{1}{ }^{2}$ (RE)Signification in the Assessment Process of Young and Adult SubJeCtS WITH INTELLECTUAL DISABILITY
}

\author{
Elisiane Perufo ALLES 3 \\ Sabrina Fernandes de CASTRO ${ }^{4}$ \\ Eliana da Costa Pereira MENEZES 5 \\ Cláudia Adriane Graeff DICKEL ${ }^{6}$
}

\begin{abstract}
RESUMO: Este artigo objetiva problematizar o processo de avaliaçáo do sujeito com Deficiência Intelectual (DI) e seus efeitos em termos de definiçáo, de classificaçáo e de diagnósticos produzidos sobre a DI. As discussóes propostas partem de uma análise referente às diferentes abordagens presentes nos manuais da Associação Americana de Deficiência Intelectual e de Desenvolvimento (AAIDD, 2010 e AAMR, 2006) e suas (re)significaçóes. Procuramos colocar sob tensionamento discursos utilizados para delimitar quem são os sujeitos com DI; que características os constituem; que comportamentos os caracterizam; que potencialidades em termos de aprendizagens eles possuem e que apoios necessitam no contexto educacional. Em articulação com tais análises, apresentamos os dados produzidos no projeto "As contribuiçôes do Rio Grande do Sul para a validação da Escala de Intensidade de Suporte - SIS no Brasil”. Amparadas teoricamente nas discussóes socioantropológicas propostas por Lev S. Vigotski, tomamos tais dados como elementos para a construçâo de uma análise que nos possibilite indicar que faz-se possível (e necessário) um olhar para a DI que não parta dos indicadores de QI, historicamente responsável pela delimitaçáo da DI em níveis de severidade, cujas possibilidades de desenvolvimento passaram a ser antecipadamente indicadas pelos diagnósticos clínicos. Nesse sentido, entendemos que, ao deslocarmos a ênfase do diagnóstico do QI para os sistemas de apoio, passamos a perceber um sujeito produzido nas práticas culturais, cujas possibilidades de desenvolvimento e aprendizagem não são exclusivamente determinadas pelos seus aspectos biológicos, mas, sim e principalmente, pelas interaçóes sociais que ele estabelece ao longo de seu desenvolvimento.
\end{abstract}

PALAVRAS-CHAVE: Educação Especial. Deficiência Intelectual. Desenvolvimento. Sistemas de Apoio. Práticas Culturais.

\begin{abstract}
This paper aims at problematizing the assessment process of subjects with Intellectual Disabilities (ID), and its effects in terms of definition, classification and diagnoses produced on ID. The proposed discussions stem from an analysis of the different approaches presented in the manuals of the American Association for Intellectual and Developmental Disability (AAIDD, 2010 and AAMR, 2006) and their (re)significations. We seek to put under tension the discourses used to define who the subjects with ID are; what characteristics constitute them; what behaviors characterize them; what learning potential they have and what supports they need in the educational context. In articulation with these analyzes, we present data produced in the project "The contributions of Rio Grande do Sul for the validation of the Support Intensity Scale - SIS, in Brazil". Based theoretically on the socio-anthropological discussions proposed by Lev S. Vygotsky, we consider the data as elements for the construction of an analysis that indicates the possibility (and necessity) to look at the ID from a perspective other than one that derives from IQ indicators, which are historically responsible for the delimitation of ID in levels of severity, whose development possibilities were previously indicated by clinical diagnoses.
\end{abstract}

KEYWORDS: Special Education. Intellectual Disability. Development. Support systems. Cultural practices.

\footnotetext{
${ }^{1}$ http://dx.doi.org/10.1590/s1413-65382519000300002

${ }^{2}$ Projeto financiado com bolsas pelos programas 'Fundo de Incentivo à Pesquisa' (FIPE) e 'Programa de Licenciaturas' (PROLICEN) da Universidade Federal de Santa Maria/UFSM.

${ }^{3}$ Mestranda em Educação pela Universidade Federal do Paraná. Graduada em Pedagogia e Educação Especial pela Universidade Federal de Santa Maria. alles.elisiane@gmail.com. Santa Maria/Rio Grande do Sul/Brasil.ORCID: https://orcid.org/0000-0003-0178-7442

${ }^{4}$ Professora Adjunta do Departamento de Educação Especial, Centro de Educação da Universidade Federal de Santa Maria. sabrinafcastro@gmail.com. Santa Maria/Rio Grande do Sul/Brasil. ORCID: https://orcid.org/0000-0002-2204-6136

${ }^{5}$ Professora Associada do Departamento de Educação Especial, Centro de Educação da Universidade Federal de Santa Maria. elianacpm@hotmail.com. Santa Maria/Rio Grande do Sul/Brasil. ORCID: https://orcid.org/0000-0002-5908-0039

${ }^{6}$ Professora da rede privada, graduada em Pedagogia e Educação Especial pela Universidade Federal de Santa Maria. kaudickel@ gmail.com. Santa Maria/Rio Grande do Sul/Brasil. ORCID: https://orcid.org/0000-0002-7200-3927
} 


\section{LOCALIZAÇÓES INICIAIS SOBRE ESCOLHAS TEÓRICO-METODOLÓGICAS}

Este trabalho é resultante de uma pesquisa que vem sendo desenvolvida no Rio Grande do Sul/Brasil desde maio de 2014, a partir de uma parceria entre pesquisadores da Universidade Federal de Santa Maria (UFSM) e da Universidade Federal de São Carlos (UFSCar). O projeto de "Adaptação e Validação da Escala de Intensidade de Suporte - SIS para o Brasil" é coordenado pela Profa. Dra. Maria Amélia Almeida, vinculada à UFSCar. Já em âmbito regional, está sendo desenvolvido, junto à UFSM, o projeto "As Contribuiçôes do Rio Grande do Sul para a validação da escala de Intensidade de Suporte - SIS no Brasil”.

A Escala de Intensidade de Apoio - SIS (Supports Intensity Scale) tem "como finalidade mensurar a intensidade da necessidade de suporte/apoio que uma pessoa com deficiência intelectual precisa para relacionar-se, viver e conviver de acordo com as demandas da sociedade atual" (Almeida, 2013, p. 14). Desse modo, a Escala é um instrumento de avaliação que foca no nível de apoio que o sujeito necessita, contribuindo para o desenvolvimento de planejamentos educacionais individualizados centrado nas áreas que o sujeito com deficiência intelectual (DI) necessita de mais apoio.

A definição de apoio foi proposta pela Associação Americana de Deficiência Intelectual e de Desenvolvimento [AAIDD] (2010, p. 109) como o conjunto de "recursos e estratégias que visam promover o desenvolvimento, educação, interesses e bem-estar pessoal de uma pessoa e aprimorar o funcionamento individual”. Já a necessidade de apoio refere-se “ao padrão e intensidade dos apoios necessários para que uma pessoa participe em atividades ligadas ao funcionamento humano normativo". Dessa forma, são apresentados quatro níveis de apoio: Intermitente, fornecido conforme a necessidade do sujeito e por períodos curtos de tempo ao longo da vida; Limitado, caracterizado por consistência ao longo do tempo em ambiente específico durante tempo limitado; Amplo, refere-se ao apoio regular em alguns ambientes e não caracterizado por tempo limitado; e, por fim, Permanente, oferecido com alta intensidade, longa duração ou ao longo da vida e, muitas vezes, envolve vários profissionais e diferentes ambientes de atendimento (AAIDD, 2010; Almeida, 2004; Zutiāo, 2016).

A SIS é composta por três seções (Thompson et al., 2004): Seção 1 - Escala de Necessidade de Apoio, que consiste em 49 atividades que estão agrupadas em seis subescalas de apoio; Seção 2 - subescala suplementar, consiste em oito itens relacionados à atividade de Proteção e Defesa; e Seção 3 - Necessidades de Apoio Médico e Comportamental Excepcionais, que inclui 15 condiçóes médicas e 13 problemas comportamentais que tipicamente requerem maiores níveis de apoio, independentemente das necessidades de apoio relativo a outras áreas de atividades da vida.

Cabe salientarmos que os totais da Seção 1 são resultantes da frequência, do tempo diário e do tipo de apoio que o sujeito necessita para desempenhar as atividades apresentadas em cada item da subescala. Essa seção é dividida em seis subescalas: Vida Diária (Parte A); Vida em Comunidade (Parte B); Aprendizagem ao Longo da Vida (Parte C); Emprego (Parte D); Saúde e Segurança (Parte E); e Sociais (Parte F).

Assim, esse instrumento tem por objetivo a avaliação dos níveis de apoio necessários nas atividades do dia a dia de jovens e adultos com deficiência intelectual, abrangendo as seguintes áreas: atividades de vida diária; atividades de vida em comunidade; atividades de apren- 
dizagem ao longo da vida; atividades de emprego; atividades de saúde e segurança; atividades sociais; e atividades de proteção e defesa.

Participaram da pesquisa do Rio Grande do Sul 66 jovens e/ou adultos com deficiência intelectual e/ou seus responsáveis legais ou profissionais que trabalham, prestam assistência a ele/ela há mais de três meses ${ }^{7}$. Para participação na pesquisa, um dos critérios de seleção é o sujeito possuir diagnóstico clínico. A aplicação da escala foi realizada com os seguintes percentuais de participantes de acordo com o nível intelectual: 42,4\% das escalas foram aplicadas com jovens e adultos com deficiência intelectual leve; 36,4\% com deficiência intelectual moderada; 7,6\% com deficiência intelectual severa; e 13,6\% aplicada em jovens e adultos com deficiência intelectual profunda.

O projeto foi composto por seis etapas: Para a coleta dos dados foram seguidas três, a saber: Etapa 1. Contato inicial com as entidades; Etapa 2. Agendamento das visitas nas entidades participantes; Etapa 3. Aplicação da Escala de Intensidade de Apoio (SIS - Brasil).

As análises dos dados seguiram mais duas etapas: Etapa 4. Digitação dos dados coletados e envio dos dados para a equipe do projeto nacional; e Etapa 5. Procedimento de análise de dados locais de acordo com as instruçóes da Escala SIS; desse modo, os dados foram inseridos no Software SPSS Statistic e, para evidenciar a validade da escala, foram realizados testes estatísticos (como o de correlação de Pearson).

Após a coleta e a análise de dados, uma etapa extra foi adicionada ao projeto: Etapa 6. Produção do relatório individual de cada participante com o resultado da SIS e algumas sugestóes para elaboração do Planejamento Educacional Individualizado - PEI (esse relatório foi entregue às instituiçôes participantes).

Fragmentos dessa análise produzida sobre os dados coletados no projeto, especificamente aqueles coletados pelas pesquisadoras da UFSM, constituem a continuidade do presente texto, cujo objetivo é problematizar o processo de avaliação do sujeito com DI e seus efeitos em termos de definição, classificação e diagnósticos. Para viabilizar essa problematização, centramos a análise nas questóes relativas ao item $\mathrm{C}$ da Escala - Atividades de aprendizagem ao longo da vida. O item C é composto por nove subitens, quais sejam: C1 - Interagir com outras pessoas em atividades de aprendizagem; C2 - Participar nas decisões sobre a própria educação e formação; C3 - Aprender e usar estratégias para resolução de problemas; C4 - Utilizar tecnologia para aprender; C5 - Acessar contextos educacionais e de formação; C6 - Aprender competências acadêmicas funcionais (ler sinais, contar o troco, etc.); C7 - Aprender habilidades para a saúde e atividades físicas; C8 - Aprender habilidades de autodeterminação; e C9 - Aprender estratégias de autogerenciamento.

A escolha do item $\mathrm{C}$ especificamente deu-se por entendermos que a proposta de avaliação apresentada pela SIS, centrada na atual definição de DI proposta pela AAIDD (2010),

\footnotetext{
7 Salientamos que o projeto nacional foi aprovado pelo Comitê de Ética em Pesquisa da Universidade Federal de São Carlos (aprovado pelo Parecer no 462.550, de 10 de dezembro de 2013). Ainda, antes do início da coleta dos dados, os participantes assinaram os Termos de acordo com o nível de participação (a saber, os Termos utilizados na pesquisa são: Termos de Consentimento Livre Esclarecido Institucional, Termos de Consentimento Livre Esclarecido aos Participantes, Termo de Consentimento Livre Esclarecido aos Responsáveis legais dos jovens e adultos com deficiência intelectual e o Termo de Assentimento para a pessoa com deficiência).
} 
ao deslocar o foco do processo avaliativo e diagnóstico dos níveis de severidade e realocá-lo nos níveis de apoio, produz outras formas de classificação da DI e pode produzir efeitos significativos nos processos de desenvolvimento e aprendizagem dos sujeitos, como discutiremos na sequência do texto.

\section{DEFICIÊNCIA INTELECTUAL: DAS PRIMEIRAS DEFINIÇỐS E CLASSIFICAÇÓES AO PROCESSO DIAGNÓSTICO ATUAL}

No atual contexto educacional, orientado a partir de princípios inclusivos, a presença de alunos com deficiência nas escolas regulares é uma realidade frequente. Produzidos historicamente a partir da aliança de saberes médicos e saberes pedagógicos, os sujeitos com deficiência intelectual carregam ainda hoje estigmas limitantes com relação as suas possibilidades e potencialidades de aprendizagem e desenvolvimento. $\mathrm{O}$ significado de deficiência intelectual, hoje legitimado pela saúde em aliança com a escola, resulta de um longo processo histórico operado sobre a infância (escolarizada) em busca da identificação e definição da anormalidade. Tais questôes foram aqui discutidas a partir da interlocução entre a proposição conceitual atual de deficiência intelectual e os embasamentos teóricos da perspectiva vigotskiana. Parece-nos que os efeitos da interlocução entre essas instâncias podem ser significativamente produtivos para a (re)significação dos processos de escolarização ofertados aos alunos em questão e especialmente potentes para a superação de práticas desenvolvidas ainda hoje sob um viés clínico, produzido historicamente de forma limitante, que, sem dúvida, precisa ser superado.

Ao iniciarmos as análises aqui propostas com a discussão de conceitos como norma/ normalidade/normalização e escola/escolarização, queremos problematizar a aliança entre saberes médicos e as práticas escolares, estabelecida de forma privilegiada a partir do início do século XX, procurando discutir seus efeitos na constituição da criança anormal. Essa discussão mostra-se especialmente potente porque é exatamente a identificação da criança anormal, que se dá pela produção de saberes da psiquiatria sobre comportamentos inicialmente classificados como imbecilidade, demência, alienação, estupidez, que vimos emergir no século XIX teorias pedagógicas destinadas à escolarização daqueles considerados "idiotas", hoje "deficientes intelectuais".

Como nos indica Silva et al. (2007, p. 5): "Para melhor compreendermos a emergência histórica da criança anormal, torna-se necessário desmontar o passado para buscar, na idiotia, as linhas de construção que lhe deram origem”. Nesse sentido, toma-se o século XIX como um marco na identificação da criança anormal, a partir da diferenciação daquilo que constituiria certas doenças mentais, presentes nos sujeitos com desenvolvimento intelectual preservado, e aquilo que constituiria uma incapacidade de desenvolvimento intelectual. Segundo os autores citados, anteriormente a essa definição, imbecilidade, estupidez, demência constituíam quadros de loucura, que, por sua vez, era definida a partir do conceito de delírio. A imbecilidade seria caracterizada por um estado máximo de delírio, produtora de um sujeito incapaz de conceber a verdade. Nesse contexto, "o idiotismo era descrito como uma forma total e absoluta da loucura” (Silva et al., 2007, p. 5).

\footnotetext{
${ }^{8} \mathrm{O}$ termo "idiotia" será aqui utilizado em uma referência à terminologia utilizada no contexto das primeiras descobertas sobre a deficiência intelectual.
} 
Em oposiçãao a essa definição, no século XIX, vimos a produção da separação entre os sujeitos que pertenciam à condição de doentes, sendo, portanto, passíveis de tratamento e cura, e aqueles classificados no quadro de monstruosidades gerais, a quem restava, desde sua identificação, o status de incurabilidade e incapacidade que resultam até os dias atuais em representações estigmatizantes e limitadoras sobre o sujeito com deficiência intelectual.

A idiotia não é uma doença, é um estado no qual as faculdades intelectuais não se manifestam jamais, ou não puderam se desenvolver o suficiente para que o idiota pudesse adquirir os conhecimentos relativos à educaçáo que recebem os indivíduos de sua idade, e colocados nas mesmas condiçôes que eles. A idiotia começa com a vida ou na idade que precede o desenvolvimento completo das faculdades intelectuais e afetivas; os idiotas são aqueles que o serão durante todo o curso de sua vida, e neles tudo revela uma organizaçáo imperfeita ou uma parada no seu desenvolvimento. Não se concebe a possibilidade de mudar tal estado. (Esquirol, 1818 como citado em Pessotti, 2012, p. 91).

Essa noção de idiotia cunhada por Esquirol indica como elemento importante para o diagnóstico o conceito de desenvolvimento. "A idiotia seria uma ausência de desenvolvimento, na qual as faculdades intelectuais nunca se manifestariam ou não poderiam se desenvolver, caracterizando-se por uma forma estável e sem possibilidades de evolução” (Silva, Pires, Scisleski, \& Hartmann, 2010, p. 404). Temos então o conceito de desenvolvimento delimitando aquilo que caracterizaria a loucura, uma doença mental - compreendida como um problema de desenvolvimento - e aquilo que caracterizaria a idiotia (hoje deficiência intelectual) - compreendida pela ausência de desenvolvimento.

O homem louco é privado dos bens de que outrora gozava: é um rico tornado pobre. O idiota sempre esteve no infortúnio e na miséria. O estado do homem louco pode variar; o do idiota é sempre o mesmo. Este tem muitos tratos da infância, aquele conserva muito da fisionomia do homem feito. Em ambos, as sensações são nulas, ou quase nulas; mas o homem louco, na sua organização e mesmo na sua inteligência demonstra qualquer coisa da sua perfeição de outrora; o idiota é o que sempre foi, é tudo o que sempre foi, é tudo o que pode ser, relativamente à sua organização primitiva [...]. (Esquirol, 1818 como citado em Pessotti, 2012, p. 91).

Esquirol aponta assim para a primeira diferenciação clara entre idiotia e loucura (e seus derivados), podendo, a partir dela, ser diagnosticada a loucura como perda da razão e a idiotia como ausência daquela, desde a infância, em função de problemas na infância ou de condiçóes pré-natais ou perinatais (Pessotti, 2012). Aqui já é possível perceber anúncios do conceito de deficiência intelectual que perduram até os dias atuais: a ideia da origem orgânica, sua incurabilidade e seu aparecimento ainda na infância.

A partir de Silva et al. (2010), podemos apontar Édouard Séguin, do século XIX, como o responsável pela produção de uma nova compreensão sobre o conceito de idiotia, tomando como elemento central para essa definição o conceito de desenvolvimento, cunhado por Esquirol, ressignificando-o. Segundo Séguin, o idiota não é alguém cujo desenvolvimento não se manifesta, mas, sim, alguém cujo desenvolvimento foi interrompido. O desenvolvimento em Séguin é uma conquista de todo e qualquer indivíduo, "[...] é como uma regra de sucessão cronológica com um momento de chegada ideal, seguindo uma linearidade temporal" (Silva et al., 2010, p. 404). Nessa compreensão de desenvolvimento, é possível localizarmos 
também a emergência de padróes de normalidade e seus correlatos significados de anormalidade. Se há um percurso prévio de desenvolvimento, delimitado por uma linearidade temporal, cujo destino ideal de chegada (que se daria na idade adulta) é definido para todos os sujeitos e, se há sujeitos que não conquistam esse ideal de desenvolvimento, exatamente porque sua linearidade é interrompida, temos então a indicação daqueles que não se encaixam em um padrão normativo estabelecido. Nesse caso, emerge a compreensão (e a produção) da idiotia como um estado desviante de uma norma (Silva et al., 2010). E, assim, passa-se a definir que o idiota é, na verdade, um anormal.

Uma vez decretada sua incurabilidade, resta aos especialistas a indicação de formas de manutenção desses sujeitos em condições de vida em uma coletividade social. Nesse momento, a aliança com a escola, conforme já anunciamos anteriormente, aponta como uma das mais (se não a mais) potente estratégia de normalização. Passa-se, então, a falar nas possibilidades de educabilidade do idiota. Uma vez que, “[...] ao instrumental médico, nada restava fazer em prol da melhoria das condiçóes dos idiotas, entram em cena as discussóes acerca da possibilidade de aperfeiçoamento destes por meio da educação" (SILVA et al., 2007, p. 6).

Silva et al. (2010), ao analisarem discursos produzidos pela psiquiatria no país em meados do século XX, indicaram que, naquele contexto, foi possível perceber a necessária aliança instituída pelo saber da psiquiatria (responsável pela identificação do anormal via diagnósticos clínicos) com as práticas escolares (responsável pela indicação de possíveis anormais, encaminhados para avaliação e identificação clínica).

[...] a questáo da educação torna-se crucial [...] porque a escola pode funcionar como a primeira instância profilática antes de um encaminhamento formal aos serviços de saúde mental (Scisleski, 2006). Percebe-se aqui uma estratégia do poder psiquiátrico de se expandir para além dos muros do hospital, pois, como afirma Jacintho Godoy, "não bastam apenas exames pedagógicos ou mesmo médicos, é o exame psiquiátrico que fornece a ficha completa do aluno em cada caso suspeito" (Godoy, 1955, p. 194). Ou seja, o psiquiatra requer ajuda do educador para detectar quais alunos são potencialmente capazes de possuírem uma anormalidade, cabendo táo somente a este profissional a realização dos exames que revelarão a "verdade" sobre o educando. (Silva et al., 2010, p. 403).

Temos assim a aliança entre saberes médicos e saberes pedagógicos produzindo e legitimando aqueles que necessitam de atendimento especializado, com vistas à conquista da reabilitação e da normalização. Ainda que tenhamos evoluído muito em termos conceituais em função do conhecimento científico produzido, entendemos que é nas primeiras classificações das anormalidades da infância no final do século XIX que podem ser localizadas as condições de possibilidade para a invenção, ao longo do século XX, de concepçóes diagnósticas sobre a deficiência intelectual. Tais concepçóes têm determinado aquilo que é ofertado a esses sujeitos em termos de educação escolarizada até os dias atuais.

Segundo Alles (2016, p. 10), "trabalhos e pesquisas com enfoque pedagógico" possibilitaram a ressignificação da deficiência intelectual, a partir da tentativa de abandono de enfoques centrados em aspectos puramente fisiológicos e patológicos. Para a autora, foi o século XX marcado por pesquisas cujo objetivo destinou-se à busca de uma conceituação da definição e da caracterização funcional acerca da deficiência intelectual. 
Nessa busca pela definição e pela conceituação, Alles (2016) destaca os manuais publicados pela American Associationon Mental Retardation (AAMR), fundada em 1876, tendo como primeiro presidente Séguin, e atualmente denominada como American Association of Intellectual and Developmental Disability (AAIDD). A alteração do termo "deficiência mental" por "deficiência intelectual" deu-se a partir da realização da "Conferência Internacional sobre Deficiência Intelectual”, realizada em 2001, no Canadá, por recomendação da International Association for the Scientific Study of Intellectual Disabilities (IASSID). Tal terminologia - deficiência intelectual - passa a ser a oficialmente utilizada, inclusive no Brasil, para nos referirmos ao sujeito antes classificado como sujeito com deficiência mental. Importa destacarmos que se trata de uma mudança terminológica que não altera a compreensão conceitual de tal deficiência, porém, como destacado por Pletsch e Glat (2012),

não se trata simplesmente da troca de uma expressão por um sinônimo menos estigmatizante. Esta mudança de terminologia - fruto de amplo debate nos meios científicos internacionais representa um novo paradigma em termos de definição do construto da deficiência intelectual, em processo desde a definição e classificaçáo apresentada pela então AAMR em 2002. (Pletsch \& Glat, 2012, p. 196).

Segundo Alles (2016), a publicação dos manuais e suas revisões deu-se nos anos de 1908, 1937, 1941, 1959, 1961, 1973, 1983, 1992, 2002, sendo a atual definição de 2010. Considera-se que os manuais produzidos pela referida Associação têm ocupado lugar central, tanto na definição diagnóstica da deficiência intelectual quanto na proposição de políticas públicas destinadas à escolarização e à profissionalização dos sujeitos. $\mathrm{O}$ modelo teórico apresentado na décima edição e utilizado na décima primeira edição, apresentada em 2010, dispóe um foco ecológico no qual o funcionamento individual é resultante da interação de apoios com as dimensóes de Habilidades Intelectuais; Comportamento Adaptativo; Participação; Saúde e Contexto. Cabe destacarmos que a diferença encontrada nos modelos teóricos de 2002 e 2010 é a inversão da ordem das dimensões referentes à saúde e à participação, assim como, na décima edição, a dimensão participação (terceira dimensão) referia-se também às interações e aos papeis sociais.

Entendemos ser possível visualizar aqui a proposição de modelo teórico cujo foco recai sobre uma concepção de sujeito que está em interação com o ambiente social em suas mais diversas dimensóes, o que aproxima as concepções da Associação à teorização vigotskiana. Ao indicar que é preciso analisar o sujeito com DI não exclusivamente pelos seus fatores intelectuais, mas também pelas suas possibilidades de participação na vida social via avaliação dos apoios recebidos em seus processo de desenvolvimento, a AAIDD aponta para uma conceituação de DI menos clínica, centrada náo exclusivamente no sujeito, mas principalmente em um contexto que precisa ser analisado, avaliado e (re)organizado quando necessário.

Nesse contexto, podemos verificar, na edição de 2010, que a estrutura avaliativa proposta é composta por três funçóes: diagnóstico, classificação e planejamento dos apoios, as quais apresentam os instrumentos adequados a serem utilizados a fim de atingir os objetivos de avaliação. Para tanto, faz-se necessário respeitar três critérios na estrutura avaliativa: “(a) os instrumentos e o processo de avaliação devem corresponder ao objetivo da avaliação; (b) os resultados da avaliação devem ser tão válidos quanto possível, e (c) os resultados devem ser úteis e propositadamente aplicados" (AAIDD, 2010, p. 21). 
Assim, no que tange ao diagnóstico, ele precisa apresentar como propósito específico a presença ou a ausência da deficiência intelectual e estabelecer elegibilidade para serviços, benefícios e proteçóes legais. Desse modo, a AAIDD apresenta como exemplos de instrumentos e métodos avaliativos do diagnóstico: Testes de inteligência; Escalas de comportamento adaptativo; Idade documentada de início; Medidas de desenvolvimento; História social e registros educacionais (AAIDD, 2010).

Considerando a inexistência de instrumentos de avaliação da conduta adaptativa validados no Brasil, podemos inferir que o diagnóstico de DI tem estado centrado no julgamento clínico, baseado nos manuais internacionais de classificação das doenças como o Manual Diagnóstico e Estatístico de Transtornos Mentais - DSM-5 (American Psychiatric Association [APA], 2014) e na Classificação Internacional de Doenças - CID 10 (Organização Mundial da Saúde [OMS], 1993).

No DSM-5 é-nos apresentada uma terminologia de deficiência intelectual (transtorno do desenvolvimento intelectual) apoiada na conceituação proposta pela AAIDD (2010), compreendida a partir de três critérios: déficits nas funçôes intelectuais, nas funções adaptativas e originando-se na fase de desenvolvimento. A diferença entre os dois manuais é que o conceito apresentado pela AAIDD se foca em um modelo multidimensional centrado no apoio das diferentes áreas do desenvolvimento do sujeito (habilidades intelectuais; comportamento adaptativo; saúde; participação e contexto), as quais são definidas a partir do funcionamento adaptativo do sujeito, enquanto no DSM - 5 ainda coloca a ênfase da avaliação no quociente de inteligência (QI).

Nesse sentido, entendemos que a atual conceituação de DI proposta pela AAIDD representa um avanço em termos de diagnóstico para o sujeito, uma vez que sugere que o diagnóstico de deficiência intelectual, bem como os níveis de gravidade, deveriam ser definidos com base no funcionamento adaptativo e não em escores de QI, uma vez que é o funcionamento adaptativo que determina o nível de apoio que o sujeito com DI necessita. O que queremos aqui apontar é que as (re)significaçóes propostas pela AAIDD nos indicam que se faz possível um olhar para a DI que não parta de fatores historicamente responsáveis pela delimitação da DI em níveis de severidade, cujas possibilidades de desenvolvimento passaram a ser antecipadamente indicadas pelos diagnósticos clínicos. Nesse sentido, entendemos que, ao deslocarmos a ênfase do diagnóstico do QI para os sistemas de apoio, passamos a perceber um sujeito com DI produzido nas práticas sociais, cujas possibilidades de desenvolvimento e aprendizagem não são exclusivamente determinadas pelos seus aspectos biológicos, mas, sim, e principalmente, pelas interações que ele estabelece ao longo de seu desenvolvimento.

Segundo Vigotski (2011, p. 869), "a psicologia da criança anormal foi construída, em geral, pelo método da subtração das funçóes perdidas em relação à psicologia da criança normal”. Em substituição a essa compreensão limitante, o autor defende que se considere não apenas as dificuldades impostas ao desenvolvimento pela deficiência, mas principalmente a necessidade de busca de caminhos alternativos de desenvolvimento apresentada ao organismo por essa própria deficiência. A tese do autor toma então a deficiência como um estímulo para a busca de outras formas de interação do sujeito com o meio cultural que poderiam "compensar a deficiência e conduzir todo o sistema de equilíbrio rompido a uma nova ordem” (Vigotski, 2011, p. 869). 
Temos aqui a cultura9 ${ }^{9}$ como centro do processo de constituição do homem (tenha ele ou não deficiência) e de suas formas mais complexas e superiores de pensamento.

[...] o desenvolvimento das funçóes psíquicas superiores é possível somente pelos caminhos do desenvolvimento cultural, seja ele pela linha do domínio dos meios externos da cultura (fala, escrita, aritmética), ou pela linha do aperfeiçoamento interno das próprias funçóes psíquicas (elaboração da atenção voluntária, da memória lógica, do pensamento abstrato, da formação de conceitos, do livre-arbítrio e assim por diante). As pesquisas mostram que a criança anormal, em geral, tem atrasos justamente nesse aspecto. Tal desenvolvimento não depende da deficiência orgânica. Eis por que a história do desenvolvimento cultural da criança permite propor a seguinte tese: o desenvolvimento cultural é a principal esfera em que é possível compensar a deficiência. Onde não é possivel avançar no desenvolvimento orgânico, abre-se um caminho sem limites para o desenvolvimento cultural [grifo nosso]. (VIGOTSKI, 2011, p. 869).

Como professoras que atuam na formação de professores de Educação Especial que irão trabalhar frente a alunos que possuem DI, entendemos que tal concepção (centrada no meio social) parece nos dar mais possibilidades de atuação pedagógica, ao mesmo tempo que exige da escola o exercício permanente de atenção às relaçóes que esse aluno estabelece com colegas, professores, família e demais sujeitos com quem convive. Nessa esteira, faz-se importante que as práticas desenvolvidas no contexto da escola inclusiva não estejam limitadas as açóes da Educação Especial via atendimento do aluno no espaço da sala de recursos multifuncional. Se o sujeito se constitui pelos resultados das interaçóes que estabelece, faz-se determinante que tais relaçóes sejam foco do planejamento pedagógico, o que, por sua vez, pressupóe a produção de outras formas de compreensão da DI no contexto da escola.

\section{A PROduÇáo de OUTRAS Formas de COMPREENSÁo da DEFiCIÊNCIA INTELECTUAL E SEUS POSSÍVEIS EFEITOS NOS PROCESSOS DE APRENDIZAGEM DOS SUJEITOS}

Como já indicamos, a partir da utilização da proposição da AAIDD (2010), a DI passa a ser compreendida por fatores pessoais e ambientais presentes na vida dos sujeitos. Dessa forma, é possível analisar que há uma intencionalidade de desfocar o diagnóstico do sujeito com DI de sua capacidade intelectual, alterando-o para o nível de apoio que ele irá necessitar ao desempenhar atividades sociais. Nesse contexto é que se propóe a Escala SIS (Thompson et al., 2004) como um instrumento de avaliação, cujo objetivo, conforme já anunciado, é mensurar a intensidade de apoio que uma pessoa com deficiência intelectual necessita para viver, conviver e relacionar-se frente à sociedade.

Assim, ao olharmos para os dados do projeto $^{10}$, que indicam questóes relativas ao item C da Escala - Atividades de aprendizagem ao longo da vida, compreendidas por tarefas necessárias para alcançar êxito em situaçóes de aprendizagem ao longo da vida, incluindo nesse item a formação profissional, encontramos as médias apresentadas na Figura 1 a seguir.

\footnotetext{
${ }^{9}$ Segundo Vigotski (2011, p. 864), há uma relação de interdependência entre vida social e cultural. Para o autor, "tudo o que é cultural é social”. A cultura, constituída por signos e ferramentas, é produto da atividade social dos homens, portanto os homens, na medida em que se desenvolvem em um meio social, produzem cultura (modificando-a) e são dela produto.

10 "As Contribuições do Rio Grande do Sul para a validação da escala de Intensidade de Suporte - SIS no Brasil", supracitado.
} 


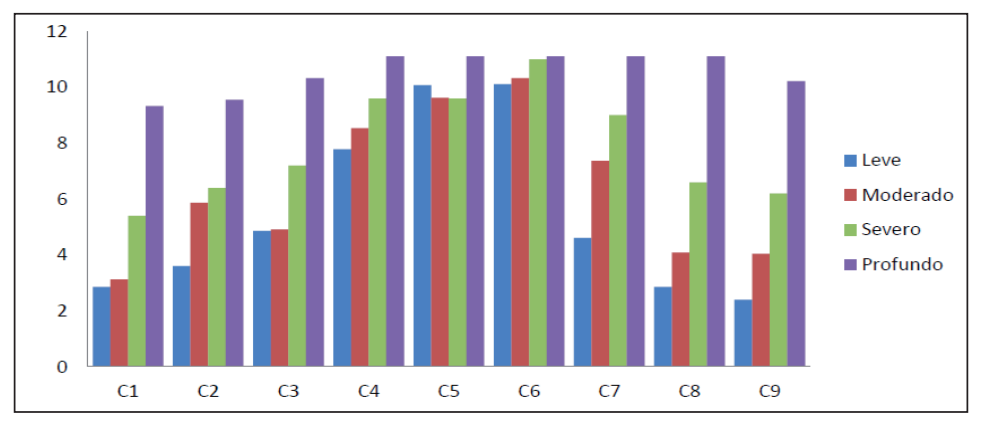

Figura 1. Médias por perguntas e nível.

Fonte: Dados obtidos no projeto "Contribuiçôes do Rio Grande do Sul para a Validação da Escala de Intensidade de Suporte - SIS no Brasil”, 2014.

Os resultados relacionados às atividades de aprendizagem ao longo da vida ${ }^{11}$ apontam, como pode ser observado no gráfico da Figura 1, para um certo nivelamento da necessidade de apoio para todos os sujeitos nos itens C5 (Acessar contextos educacionais e de formação) e C6 (Aprender competências acadêmicas e funcionais). Esses são os itens em que os sujeitos necessitam de maior apoio, tanto aqueles classificados no nível leve e moderado de DI, quanto os sujeitos com nível severo e profundo. Ainda, podemos perceber que, no item C5, ocorre uma pequena inversão entre os níveis leve e o moderado e um nivelamento entre o moderado e o severo. Esses fatores levam-nos a questionamentos em relação aos apoios oferecidos a esses sujeitos, pois o gráfico indica que, em relação à aprendizagem, mais especificamente ao acesso a contextos educacionais e de formação, e à aprendizagem de competências acadêmicas funcionais (como ler sinais, contar o troco, utilizar um relógio), os sujeitos pesquisados não apresentaram grandes diferenças de necessidade de apoio, mesmo possuindo diagnósticos clínicos de DI diferentes segundo níveis de severidade.

Segundo os dados coletados, podemos considerar que 16 dos sujeitos que possuem idade entre 31 e 41 anos e, também, 30 sujeitos com idade entre 20 e 30 anos, iniciaram seu processo de escolarização em um período em que a educação especial no Brasil iniciava a organizar suas práticas na perspectiva da educação inclusiva, procurando promover o desenvolvimento do sujeito com deficiência via escolarização no sistema comum de ensino. No entanto, ainda que tenham presenciado o início desse processo no país, tais sujeitos acabaram vivenciando experiências educacionais por um período de tempo significativo em instituições especializadas. Esse fator pode ter interferido em seus processos de desenvolvimento e assim ter ocasionado essa necessidade maior de apoio em atividades como aprender as competências acadêmicas funcionais e também o acesso a contextos educacionais. Nesse sentido, a Figura 2 mostra a escolaridade dos sujeitos.

\footnotetext{
${ }^{11}$ Para fins didáticos, retomamos aqui o detalhamento do item C da Escala - Atividades de aprendizagem ao longo da vida, já apresentado no início do texto: C1 - Interagir com outras pessoas em atividades de aprendizagem; C2 - Participar nas decisóes sobre a própria educação e formação; C3 - Aprender e usar estratégias para resolução de problemas; C4 - Utilizar tecnologia para aprender; C5 - Acessar contextos educacionais e de formação; C6 - Aprender competências acadêmicas funcionais (ler sinais, contar o troco, etc.); C7 - Aprender habilidades para a saúde e atividades físicas; C8 - Aprender habilidades de autodeterminação; e C9 - Aprender estratégias de autogerenciamento.
} 


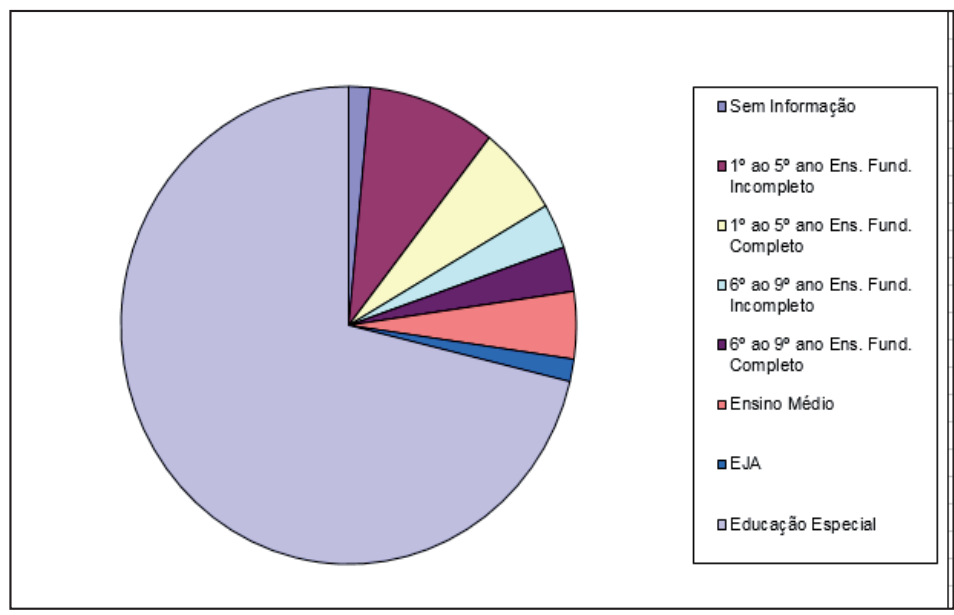

Figura 2. Escolaridade.

Fonte: Dados obtidos no projeto "Contribuiçôes do Rio Grande do Sul para a Validação da Escala de Intensidade de Suporte - SIS no Brasil”, 2014.

Conforme nos mostra a Figura 2, dos 66 sujeitos que participaram do estudo, 47 possuíam apenas a Educação Especial como meio de escolaridade. Se considerarmos, conforme nos aponta Vygotsky, que é pelas experiências vivenciadas em processos de escolarização formal que os sujeitos constroem conceitos científicos que, por sua vez, possibilitam o desenvolvimento de funçóes psicológicas cada vez mais complexas, talvez possamos inferir que as práticas de escolarizaçáo ofertadas aos sujeitos do estudo em espaços específicos de Educação Especial por longos períodos podem ter produzido possibilidades restritas de interação desses sujeitos e o mundo que os cerca. Essas interaçóes, ao não viabilizarem o desenvolvimento de conceitos científicos, produzem a estagnação dos processos de significação do mundo a partir de conceitos que o autor chama de "cotidianos". Nesse contexto, produz-se um sujeito com DI que atua no mundo com limitada autonomia no desenvolvimento de competências acadêmicas e funcionais e dificuldade para ingressar e permanecer em espaços educacionais e de formação e, posteriormente, no mundo do trabalho.

Para Beyer (2013), a história da Educação Especial mostra-nos que as escolas especiais buscavam desenvolver atividades utilizando recursos metodológicos concretos e manuais, amparadas em uma compreensão de deficiência demasiadamente terapêutica, centradas na falta e na impossibilidade de desenvolvimento, resultando em uma estagnaçáo em processos de pensamento mais elementares. Segundo o autor, o fator que merece mais atençáo quanto ao processo exclusivo de escolarização de pessoas com deficiência em espaços específicos de Educação Especial diz respeito ao prejuízo nas trocas interpsicológicas. Amparado em Vigotski, o autor salienta que "a escolarização das crianças com deficiência em grupos de crianças 'especiais', com condição individual similar, acabaria por provocar um processo de limitação social, na medida em que as trocas interpsicológicas se restringiriam às feitas no grupo de 'iguais'" (Beyer, 2005, p. 2). 
Ao tomarmos a cultura e as interaçóes sociais como fontes do processo de desenvolvimento, assumimos a importância da convivência entre sujeitos que se encontram em momentos diferentes de aprendizagem. É pelas trocas estabelecidas no meio social que os sujeitos são apresentados aos desafios que servem como propulsores para a construção de formas mais complexas de pensamento. Nesse sentido, parece-nos importante refletir sobre as formas de convivência que os sujeitos que participaram do estudo puderam estabelecer em suas histórias de vida.

Por defendermos a importância dessa reflexão, é que visualizamos, na proposição conceitual de DI da AAIDD (2010), uma outra possibilidade de constituição dos sujeitos. Como vimos, tal proposição retira o foco do sujeito e desloca-o para o contexto, a partir da indicação da possibilidade de identificação dos apoios necessários para cada um em específico, ou seja, centrado no próprio sujeito. Uma vez identificados os apoios necessários, o objetivo do trabalho educativo passa a ser ofertar tais apoios para que os sujeitos possam gradativamente deixar de necessitá-los.

Novamente aqui ressaltamos a potente interlocução entre essa compreensão de DI e a perspectiva teórica de Vygotsky. Segundo Vigotski (1997), o desenvolvimento ocorre por meio da relação e da correlação entre as estruturas elementares (reflexos, reaçóes automáticas, associações simples, entre outras) condicionadas por determinantes biológicos, e as estruturas que surgem por meio da interação na cultura, as quais são designadas como processos psicológicos superiores, a partir dos quais é encontrada a capacidade de formação de conceitos (Pletsch, 2013). Desse modo, o processo de formação conceitual está intimamente ligado à constituição histórico-cultural do ser humano e, nessa lógica, o autor afirma que a aprendizagem de conceitos ocorre antes mesmo de o sujeito ter contato com o ambiente escolar, pois ocorre por meio das interaçóes que são estabelecidas com o mundo.

Considerando então essa necessidade de se estabelecer trocas qualitativas entre os sujeitos, talvez seja possível afirmar que o espaço da escola inclusiva, quando efetiva tais trocas, pode se constituir como um espaço potente para o desenvolvimento dos sujeitos com deficiência. Nesse sentido, o projeto de inclusão escolar se efetivaria a partir da ampliação da convivência entre diferenças interpessoais, em um espaço sem delimitaçóes de capacidades a priori estabelecidas, que possibilitasse trocas psicossociais indispensáveis para o desenvolvimento de todos os alunos (Beyer, 2005).

O grande problema ou grande obstáculo quando pensamos na criança com deficiência reside no isolamento frequente que vivencia, seja na família, seja na vida escolar, seja na vida em sociedade. $\mathrm{O}$ isolamento, na ótica vygotskiana, não constitui apenas um problema social ou ético, porém apresenta uma faceta psicossocial (mais correto afirmar, psicológica) muito delicada. Esta vulnerabilidade deve-se à premissa vygotskiana central da necessidade da dinâmica sócio gênica para um desenvolvimento infantil sadio. Quanto mais intensas e positivas forem às trocas psicossociais, mais fortalecido sairá o desenvolvimento infantil, sendo a recíproca verdadeira, isto é, quanto mais debilitadas forem estas trocas, mais lacunar será tal desenvolvimento. (Beyer, 2005, p. 1).

Com isso, pensar em ambientes que proporcionem o desenvolvimento de sujeitos com deficiência é considerar em um ambiente que proporcione não somente o desenvolvimento de aspectos afetivos, mas também cognitivos e sociais. Ao olharmos para a escola a partir desses princípios, passamos a compreender o professor como um mediador que, ao se 
relacionar com o aluno em processo de inclusão escolar, leva em consideração as características pessoais de cada aluno, as formas específicas de aprendizagem que apresentam, sua bagagem cultural e intelectual.

Nessa concepção, as histórias de vida de cada um são compreendidas como elementos necessários para a construção de planejamentos individualizados, propostos a partir dos apoios identificados como necessários para que esses alunos passem a interagir de forma independente, ou com o mínimo de apoio possível, na sociedade. Assim, para possibilitar a aprendizagem e o desenvolvimento do aluno, faz-se necessário deixar de lado os diagnósticos pré-estabelecidos e passar a pensar, então, no sujeito e nas relações estabelecidas ao longo da vida.

\section{CONSIDERAÇÓES FINAIS: ASPECTOS IMPORTANTES PARA A CONTINUIDADE DA DISCUSSÃO}

Ao propormos essa discussão, objetivávamos problematizar o processo de avaliação do sujeito com DI e os efeitos em termos de definição, classificação e diagnósticos do sujeito. A partir de fragmentos do exercício analítico desenvolvido no contexto do projeto "As contribuiçóes do Rio Grande do Sul para a validação da Escala de Intensidade de Suporte - SIS no Brasil", mais especificamente das análises realizadas sobre os dados coletados acerca das atividades de aprendizagem ao longo da vida (parte C da SIS), procuramos indicar o quanto o olhar destinado ao sujeito, quando se fundamenta em uma compreensão de deficiência como falta ou impossibilidade, pode limitar suas condiçôes de aprendizagem e de desenvolvimento.

Sob essa óptica, é que compreendemos as limitaçóes e a significativa necessidade de apoios apresentada pelos sujeitos do estudo nas questóes relativas ao acesso a contextos educacionais e de formação e a conquista de aprendizagens e competências acadêmicas e funcionais. Ao considerarmos que 69,7\% dos sujeitos do estudo possuem idade superior a 20 anos, apontamos para o fato de que suas histórias de escolarização coincidem com a emergência das políticas de inclusão escolar no país. No entanto, os dados indicam que ainda que eles tenham vivenciado esse contexto de políticas educacionais inclusivas, a maioria integralizou seus processos de escolarização exclusivamente em espaços especiais de ensino.

Considerando os estudos de Vygotsky, olhamos para a história das práticas de Educação Especial, desenvolvidas desde sua origem, a partir de uma concepção clínica de deficiência, como práticas que podem produzir como efeito sujeitos com limitada condição de vida autônoma. Ao assumirmos tal posicionamento, não pretendemos desenvolver uma simples defesa da escola inclusiva ou desvalorização dos espaços de Educação Especial. O que nos parece potente é a possibilidade de ressaltarmos o caráter cultural presente no desenvolvimento dos sujeitos que coloca as interaçóes sociais em lugar de destaque nos processos de sua aprendizagem e de seu desenvolvimento. Nessa perspectiva, entendemos que, antes de nos preocuparmos em indicar espaços mais adequados para os processos de escolarização, faz-se necessário dar ênfase à uma possibilidade de avaliação e de planejamento pedagógico que parta das histórias individuais e dos sistemas de apoio que foram ou são necessários aos sujeitos.

Ao estabelecer uma articulação entre a conceituação de DI proposta pela AAIDD (2010) cujo foco recai sobre os níveis de apoio necessários para a conquista de uma vida autônoma e a perspectiva Teórica Vygotskiana, objetivamos destacar a potência dessa conceituação para a produção de outras possibilidades de interação entre o sujeito com DI, a escola e a 
sociedade. Tais interaçóes não seriam antecipadamente determinadas (e limitadas) pelos diagnósticos e prognósticos clínicos, determinados pelo nível de QI, mas, sim, pelo potencial de desenvolvimento e de aprendizagem que constitui cada sujeito e que determina uma maneira única e peculiar de estar no mundo. Nessa esteira, passamos a perceber um sujeito produzido nas práticas culturais, cujas possibilidades de desenvolvimento e aprendizagem não são exclusivamente determinadas pelos seus aspectos biológicos, mas, sim e principalmente, pelas interaçóes sociais que ele estabelece ao longo de seu desenvolvimento.

Para finalizarmos, compreendemos que, ao destacarmos novas possibilidades de compreensão da DI, podemos provocar modificaçóes nas práticas realizadas pela Educação Especial nos contextos de escolarização dos sujeitos com deficiência. Práticas estas que (re) signifiquem a ação do professor de Educação Especial como uma ação voltada às interaçóes que são estabelecidas entre os alunos com DI e os demais sujeitos no contexto escolar. Tais formas de significação podem também provocar mudanças nos processos formativos desse professor, uma vez que a proposição de formas de avaliação, diagnóstico e conceituação de DI centradas nos níveis de apoio pressupóe um professor que compreenda o sujeito como produto da complexa indissociabilidade entre os aspectos orgânicos e sociais nos processos de aprendizagem e desenvolvimento, e que efetivamente assumam tais aspectos ao construir seus planejamentos.

\section{REFERÊNCIAS}

Association of Intellectual and Developmental Disability. (2010). Intellectual disability: definition, classification, and systems of supports (11th ed). The AAIDD Ad Hoc Committee on Terminology and classification.

American Association on Mental Retardation. (2006). Retardo mental: definição, classificação e sistema de apoio (10ª. Ed.). Tradução Magda França Lopes. Porto Alegre: Artmed.

Alles, E. P. (2016). Escala de intensidade de apoio (SIS) como ferramenta de compreensão da definição de deficiência intelectual (Trabalho de Conclusão de Curso). Universidade Federal de Santa Maria, Santa Maria, Rio Grande do Sul.

Almeida, M. A. (2004). Apresentação e análise das definições de deficiência mental propostas pela AAMR - Associação Americana de Retardo Mental de 1908 a 2002. Revista de Educação, Campinas, 16, 33-48.

Almeida, M. A. (2013). Adaptação e validação da Escala de Intensidade de Suporte - SIS para o Brasil: uma contribuição para avaliação funcional de jovens e adultos com deficiência intelectual. Projeto submetido ao edital: MCTI/CNPq/MEC/CAPES No 43/2013. São Carlos.

American Psychiatric Association. (2014). DSM-5: manual diagnóstico e estatístico de transtornos mentais (5 $\mathrm{a}$ ed.). Porto Alegre: Artmed.

Beyer, H. O. (2005). Por que Lev Vygotski quando se propóe uma educação inclusiva? Revista Educação Especial, 26, 1-4.

Beyer, H. O. (2013). Inclusão e avaliação na escola: de alunos com necessidades educacionais especiais. Porto Alegre: Mediação.

Organização Mundial da Saúde. (1993). CID-10 Classificação de transtornos mentais e de comportamento. Descriçôes clínicas e diretrizes diagnósticas. Brasília: MEC/CORDE. 
Pessotti, I. (2012). Deficiência Mental da superstição à ciência. Marília: ABPEE.

Pletsch, M. D. (2013). A escolarização do aluno com deficiência intelectual... apesar do diagnóstico. In S. M. F. Meletti, \& M. C. M. Kássar (Orgs.), Escolarização de alunos com deficiência: desafios e possibilidades (pp. 243-269). Campinas, SP: Mercado das Letras.

Pletsch, M. D., \& Glat, R. (2012). A escolarização de alunos com deficiência intelectual: uma análise da aplicação do Plano de Desenvolvimento Educacional Individualizado. Linhas Críticas, 18(35), 193-208.

Silva, R. N. da, Pires, M. L., Scisleski, A. C. C., \& Hartmann, S. (2010). Anormais escolares: a psiquiatria para além dos hospitais psiquiátricos. Interface, 14(33), 401-410. DOI: http://dx.doi.org/10.1590/ S1414-32832010000200013.

Silva, I. M. da, Cruz, A. M., Lobo, L. F., Moraes, L. A. de, Santos, L. L. M. dos, Cavalcante, S. de S. et al. et. (2007). A aliança médico-pedagógica: uma genealogia do processo de exclusãoldemanda. Artigo apresentado no $14^{\circ}$ Encontro Nacional da ABRAPSO, Rio de Janeiro.

Thompson, J. R., Bryant, B. R., Schalock, R. L., Shogren, K. A., Tassé, M. J. Wehmeyer, M. L. et al. (2004). Supports Intensity Scale user's manual. Washington, DC: American Association on Mental Retardation. Versão para adaptação e validação Brasileira. Responsável: Profa. Dra. Maria Amélia Almeida/UFSCAR.

Vigotski, L. S. (2011). A defectologia e o estudo do desenvolvimento e da educação da criança anormal. Educação e Pesquisa, 37(4), 863-869.

Vigotski, L. S. (1997). Obras escogidas V. Madrid: Visor.

Zutião, P. (2016). Programa "Vida na Comunidade" para familiares de jovens com deficiência intelectual (Dissertação de Mestrado). Universidade Federal de São Carlos, São Carlos, São Paulo, Brasil.

Submetido em 25/02/2019

Reformulado em 30/05/2019

Aceito em 31/05/2019 
ALLES, E.P. et al. 